\title{
The Course Construction of Case Analysis of Financial Engineering
}

\author{
Xin Sui * \\ School of Finance \\ Nanjing University of Finance and Economics \\ Nanjing, P.R.China
}

\author{
Sige Wang, Junjie Wang, Bingbing Fu \\ School of Finance \\ Nanjing University of Finance and Economics \\ Nanjing, P.R.China
}

\begin{abstract}
In recent years, the competitions among financial institutions have become more and more intense. In such a case, financial institutions' demands for talented persons with solid financial engineering expertise are increasing day by day. At the same time, considering that risk management is one of the core tasks of financial engineering, the continuous development of internet finance also increases the demands for talented persons whose majors are financial engineering. While the course construction of case analysis of financial engineering helps students to apply what they have learned to practical cases. There is no doubt that the course construction of case analysis of financial engineering plays an important role in improving professional qualities of the students of financial engineering. Considering the aforementioned factors, the paths of the course construction of case analysis of financial engineering are analyzed from the following aspects in this paper: core tasks of financial engineering, disciplinary crossing and integration, selection of cases of financial engineering, servicing the needs of students' development, setting up the corresponding pre-courses, construction methods, laboratory conditions and other principles that need our attention.
\end{abstract}

Keywords-Financial engineering; Case analysis; Programming design; Engineering thinking

\section{INTRODUCTION}

As an emerging interdisciplinary science, financial engineering combined with finance, information technology and engineering methods can solve kinds of financial problems creatively [1]. Financial engineering has its distinguishing features and high requirements for computer and mathematical logical thinking. In recent years, with the development of Chinese financial markets, the demands for talented persons with financial engineering knowledge have increased year by year. At the same time, with the continuous development of internet finance (such as P2P online lending platform), the demands for talented persons with risk management knowledge also increase a lot. While the risk management is one of the core tasks of financial engineering [1]. It is not difficult to find that the continuous development of real economy has led to a lot of demands for professional and technical personnel with financial engineering knowledge. In such a case, lots of colleges and universities have set up the major of financial engineering and trained a batch of financial engineering graduates. In China, many universities have

This research is supported by MOE (Ministry of Education in China) Project of Humanities and Social Sciences (No.17YJC630128), Fund Project of Natural Science Research in Colleges and Universities in Jiangsu Province (No.17KJB120005, No.17KJB120004), Fund Project of Philosophy and Social Science Research in Colleges and Universities in Jiangsu Province (No.2017SJB0233, N0.2017SJB0234). formed a financial engineering training system covering all kinds of learning stages such as undergraduate, master and doctoral stages. The ability of analyzing and abstracting the real financial problems, the ability of modeling real financial problems and the ability of programming design based on the constructed models should become the necessary skills of students majoring in financial engineering. Considering this point, the construction of the curriculum system for financial engineering major should focus on cultivating the aforementioned skills and makes the above abilities become features of the major of financial engineering. In some universities, the case analysis of financial engineering is a course that is set up in the senior grade and plays an important role in further enriching students' financial engineering knowledge. The setting of the course of the case analysis of financial engineering helps students to apply what they have learned to real cases flexibly and can also help students to further understand financial engineering from the case analysis of financial engineering. However, textbooks about the case analysis of financial engineering are not enough and we can also find this point from the bigger e-commerce platforms in China ( such as Taobao shopping mall and Jingdong shopping mall). In the teaching practice of the course of the case analysis of financial engineering, some problems began to emerge. On the one hand, the content of the course of the case analysis of financial engineering is not very different from the course of financial engineering; on the other hand, the selection of financial engineering cases is divorced from the reality of China's development. Moreover, the selected cases of financial engineering cannot meet the training requirements of financial engineering students (such as mathematical logic thinking, computer programming and financial modeling). The above factors make it very hard to achieve the expected goal of the setting of the course of the case analysis of financial engineering. Wang Jinzhong (2012) published a textbook named Cases of financial engineering [2]. In this textbook, most of cases of financial engineering are virtual self-made cases and there are some differences compared with the situations in the real world. The corresponding cases are not complicated compared with the real situation and lack the training of programming ability. Due to that many financial engineering cases may involve the interests of multiple parties, not all financial engineering cases will be disclosed. In such a case, the virtual self-made cases become the main selection sources of financial engineering cases. Yang Junzhan et al. (2013) published a textbook named Application principles and cases of financial engineering. In this textbook, the training of 
programming ability are also ignored. It does not fit well with the requirements of financial engineering for improving students’ programming ability and cannot form a collaborative system with previous courses such as $\mathrm{C} / \mathrm{C}++$ programming, Matlab and its applications, and financial engineering [3]. Zhou Yujiang (2016) published a textbook named Financial engineering: theory, practice and case [4]. In this textbook, the financial engineering cases are contained. However, the content of this textbook is similar to that of the financial engineering textbook. Therefore, it's more like a textbook on financial engineering . There is no doubt that the achievements of the relative scholars and front-line teachers have laid the foundation and provided references for the construction and development of the course of case analysis of financial engineering. Based on the related research results and teaching achievements, this paper discusses and analyzes the construction path of the course of case analysis of financial engineering. During the research, on the one hand, the characteristics of financial engineering need to be considered; on the other hand, the construction path of the course should facilitate improving the professional qualities of students majoring in financial engineering and service the needs of China's economic development. In the following content, this paper explores the construction path of the course of case analysis of financial engineering from eight aspects.

\section{Construction Path of the Course of Case Analysis} OF FinANCIAL ENGINEERING

\section{A. Focus on the core tasks of financial engineering and enhance students' professional skills}

The design, pricing and risk management of financial products are the core tasks of financial engineering [1]. It is necessary for the students majoring in financial engineering to fully understand and grasp the core tasks, and reserve the corresponding professional skills. The construction path of the course of case analysis of financial engineering must also focus on and serve the core tasks of financial engineering. However, the existing construction of the course of case analysis of financial engineering mostly stays in the stage where the cases of financial engineering are collected scattered, and do not focus on the core tasks of financial engineering well. Due to that most of the cases of financial engineering are gathered scattered, there is no clear thread that runs through the whole course of case analysis of financial engineering. This leads to the unclear logic of the course system of case analysis of financial engineering, which makes the students just remember the scattered cases of financial engineering in the process of learning the course of case analysis of financial engineering, and cannot grasp the core tasks of financial engineering as a whole. Considering the core tasks of financial engineering, financial engineering cases can classified. Financial engineering cases can be classified according to the core tasks of financial engineering such as topics on the design of financial products, topics on pricing of financial products and topics on financial risk management. In this way, the features of the major of financial engineering can be fully highlighted, and the students can better understand the core tasks of financial engineering in the process of learning the course of case analysis of financial engineering. Moreover, the students can accordingly reserve relevant knowledge and enhance their professional skills. For example, in the analysis of the cases on the topics of the design of financial products, students need to master the necessary basic knowledge in financial engineering. While in the topics on pricing of financial products, students need to master the necessary pricing methods and techniques. In the topic of financial risk management, the comprehensive use of related knowledge is more emphasized. The course construction of case analysis of financial engineering considering case classification according to the core tasks of financial engineering is good for students majoring in financial engineering to fill in the lack of the relevant knowledge and is conducive to improve the level of financial engineering knowledge better and systematically.

\section{B. Pay much attention to the training of engineering thinking and advocate interdisciplinary integration of different subjects}

Just stated above, as an emerging interdisciplinary science, financial engineering combined with finance, information technology and engineering methods can solve kinds of financial problems creatively [1].One of the important features that is different from other related disciplines like finance is that students majoring in financial engineering should have a more solid mathematical basis, better programming design and modeling abilities, and have necessary engineering thinking. However, for most of the economic management majors, the setting of courses such as mathematical ability training, computer technology, programming design, modeling and simulation are not enough or even there is a lack of courses on such aspects. Due to this point, financial engineering still gives people the impression of traditional economics and management discipline in some extent. Considering that financial engineering is an emerging discipline, there is no doubt that it is very important to reveal its different features from other discipline. Therefore, its mathematical characteristics, the advantages of the computer and engineering thinking need to be reflected in its course system. While in the design of the course of case analysis of financial engineering, it is necessary to take the aforementioned factors into account. When choosing the related cases, the following aspects should be considered: a. whether the selected cases can fully train students' mathematical logic ability; b. whether the selected cases can fully mobilize the enthusiasm of students in computer programming and modeling; c. whether the selected cases can fully train students' engineering thinking. For example, when the case of the asset securitization is introduced into the case analysis course, the process of the asset securitization must be grasped as a whole. The mathematical model of the securitization pricing should be explained, and the computer simulation in the pricing process, such as the simulation of the change path of interest rate, should also be implemented by programming design. The students should learn this topic from the beginning to the end of the asset securitization. In addition, in the topic of risk managements, the technical means in other fields can be introduced to solve the risk management cases in financial engineering such as wavelet analysis [5,6,7], Copula function 
$[8,9,10]$, neural network [11,12], agent-based modeling [13,14] and support vector machine $[15,16]$. In this topic, after the corresponding mechanism is explained, the programming implementation of the corresponding mechanism in the specific financial engineering's cases should be trained. To sum up, in the design process of the course of case analysis of financial engineering, the selections of cases of financial engineering can be carried on according to the classification (such as topics on the design of financial products, topics on pricing of financial products and topics on financial risk management). Moreover, it is necessary and very important to consider the training of the students' mathematical logic ability and the promotion of the computer skills. At the same time, it is also necessary to strengthen the cultivation of the students' engineering thinking mode. The goal of the setting of the course of case analysis of financial engineering is to make financial engineering students possess excellent professional skills. The corresponding ideas can be interpreted by Fig.1.

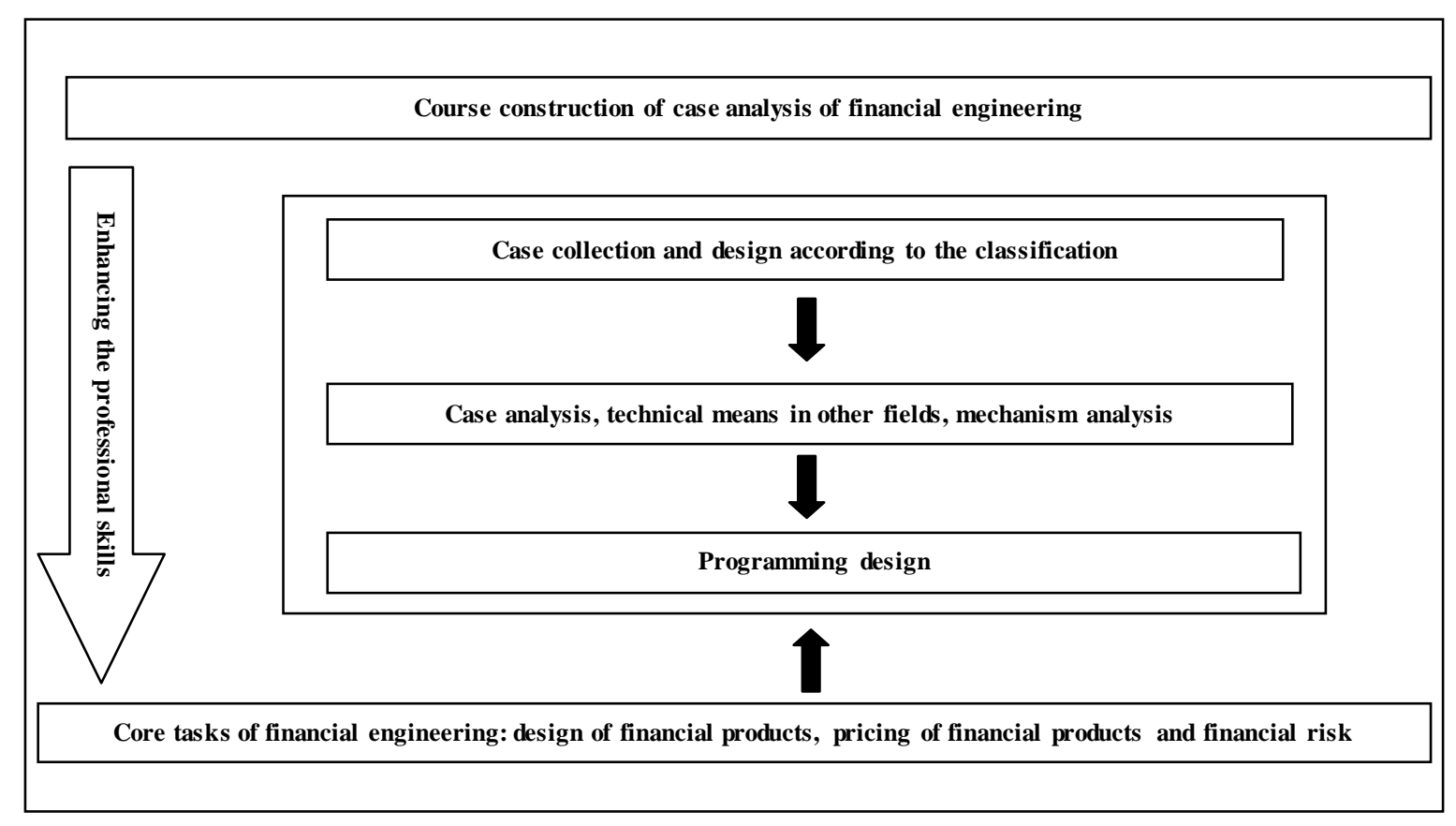

Fig. 1. Course construction of case analysis of financial engineering

\section{The selections of cases of financial engineering are based on the practice of financial development in China and guided by practical problems in China}

As a result of the limit of the total class time, the selection of materials in the course of case analysis of financial engineering should not just pursue the number of cases of financial engineering. In the process of choosing the cases of financial engineering, the cases should be more representative, problem-oriented and integral. Due to that Chinese financial market was not developed earlier, most of the cases of financial engineering in related textbooks came from many developed countries. In such a background, it makes some financial engineering students unfamiliar with Chinese derivatives trading. Some of these students even do not know whether the corresponding derivatives exist in Chinese financial market. In such a case, students are not familiar with financial engineering cases based on China's financial practice. However, recently, with the continuous development of Chinese financial market, more and more derivative products have appeared and more and more financial engineering cases have emerged. In the process of Chinese economic development, the financial innovation is gradually emerging. China Construction Bank and Biguiyuan group have issued asset-backed securities. Moreover, the products of the right of return on assets of the micro-credit company were first traded in Chongqing financial assets exchange on July 19, 2011 [17]. There is no doubt that it creates a new financing channel for the micro-credit company and also results in a new era of financial innovation for the micro-credit company [18]. What's more, several kinds of standardized derivatives have appeared in China at the right time. For example, there are CSI 300 stock index futures, CSI 500 stock index futures, SSE 50 stock index futures and treasury bond futures in China Financial Futures Exchange, SSE 50 ETF options in Shanghai stock exchange, various metal futures contracts in Shanghai Futures Exchange and the derivatives in Zhengzhou Commodity Exchange. It is very obvious that the momentum of internet financial development is relatively fierce. This has led to a large demand for financial risk management personnel. Considering this point, the selections of cases on financial risk management based on the internet financial platform in China and the development of the corresponding risk management model have a good practical significance. This will also benefit the students' employment. 


\section{Test in teaching practice and serve the needs of students' development}

The setting of any curriculum system should be put into the specific teaching practice and serves the students' future development needs. The same is true for the content setting of the course of case analysis of financial engineering. The content setting of the course of case analysis of financial engineering should also take full account of the needs of the students' development in future. For example, through the analysis of the cases on the applications of the technical means of other fields (such as wavelet analysis, Copula function, neural network agent-based modeling and support vector machine) in financial engineering, the interdisciplinary integration of multiple disciplines is advocated. In this way, the students' computer programming and financial modeling capabilities can be enhanced and their enthusiasm for research can also be stimulated at the same time. This is good for the students who plan to learn in the subsequent stages such as master stage and doctoral stage. By setting up the cases in line with the hot issues in China's economic development such as the asset securitization, the risk management of internet financial platform, the necessary professional knowledge for the students' employment is reserved. This facilitates the development of students' employment and subsequent development. Due to the different learning abilities of each student and the different future development goals of each student, the setting of the content of the course of case analysis of financial engineering should consider the problems of students' learning abilities and their diversified development goals. The students' differences should be respected and the philosophy of individualized education should be advocated in the teaching practice. In the case of no great change in the content of teaching, teachers can motivate some students to publish their relative contents or methods studied in the form of paper so as to cultivate their academic enthusiasm. While for students who are eager to work after graduation, the setting of relevant topics should consolidate relevant professional knowledge. At the same time, in order to make the setting of the content of the course of case analysis of financial engineering in line with the current situation of development in China, the related teachers of the course should enter the enterprise to carry on the corresponding investigations to better know the requirements of the employers for the necessary skills of students majoring in financial engineering, and adjust the course content in time. In sum, the content system of the course of case analysis of financial engineering is open and dynamic. It needs constantly absorbs new elements in teaching practice and serves the needs of students' future development.

\section{E. Set up the corresponding pre-courses to support the course construction of case analysis of financial engineering}

The setting of the curriculum system of some major is not independent, but a complete system supported by kinds of internal courses. Before the course of case analysis of financial engineering is set up, the students should have completed the learning of the corresponding courses. For the setting of the course of case analysis of financial engineering, in addition to common economics and management courses, the corresponding mathematical courses and computer courses are also necessary to be set for students majoring in financial engineering. For example, mathematical courses can include engineering mathematical analysis, probability theory and mathematical statistics, linear algebra, partial differential equations and so on. Computer courses can include $\mathrm{C}++$ programming, Matlab programming, financial modeling and simulation analysis, comprehensive experiment for the major of financial engineering and other computer courses that can be set. From the setting of the corresponding pre-courses, it is very obvious to find out that financial engineering majors have higher requirements for mathematical basis, computer programming and modeling abilities. There is no doubt that if the cases of financial engineering are just only analyzed and explained simply, it is not necessary to introduce the above mathematical and computer courses with higher requirements. However, the course construction of case analysis of financial engineering based on programming design needs more mathematical and computer courses to support. Such kind of the course construction will help students improve their professional kills and make financial engineering students more distinctive compared with the students of other majors.

\section{F. Comprehensive Use of Various Methods and Reasonable Setting of Teaching Contents}

During the course construction of case analysis of financial engineering, a variety of methods can be used such as the method of literature analysis, the method of the discussion, the method of the investigation and the method of the combination of teaching practice and teaching content design, as shown in Fig.2. In the following content, we will simply explain the above methods one by one.

1) Method of literature analysis: The relevant literature on the construction of the course of case analysis of financial engineering and other courses can provide reference for the course construction of case analysis of financial engineering. At the same time, the new trends in financial engineering can be found and can be introduced into the course construction in time.

2) Method of the discussion: In the course construction of case analysis of financial engineering, seminars should be held regularly to discuss the problems encountered in the teaching practice. At the same time, the related experts from the field of financial engineering as well as the related entrepreneurs should also be invited to participate in the corresponding discussion.

3) Method of the investigation: The related teachers of the course construction of case analysis of financial engineering should conduct research on the related course construction in other universities so as to obtain new reference for their own course construction. At the same time, the related teachers should enter financial institutions and enterprises to better know their demands for professional skills of students majoring in financial engineering and adjust the course content correspondingly. 
4) Method of the combination of teaching practice and teaching content design: There is no doubt the setting of any course system should be put into the specific teaching practice.
Through the feedback from the teaching practice of case analysis of financial engineering, continuous optimization of teaching content is made.

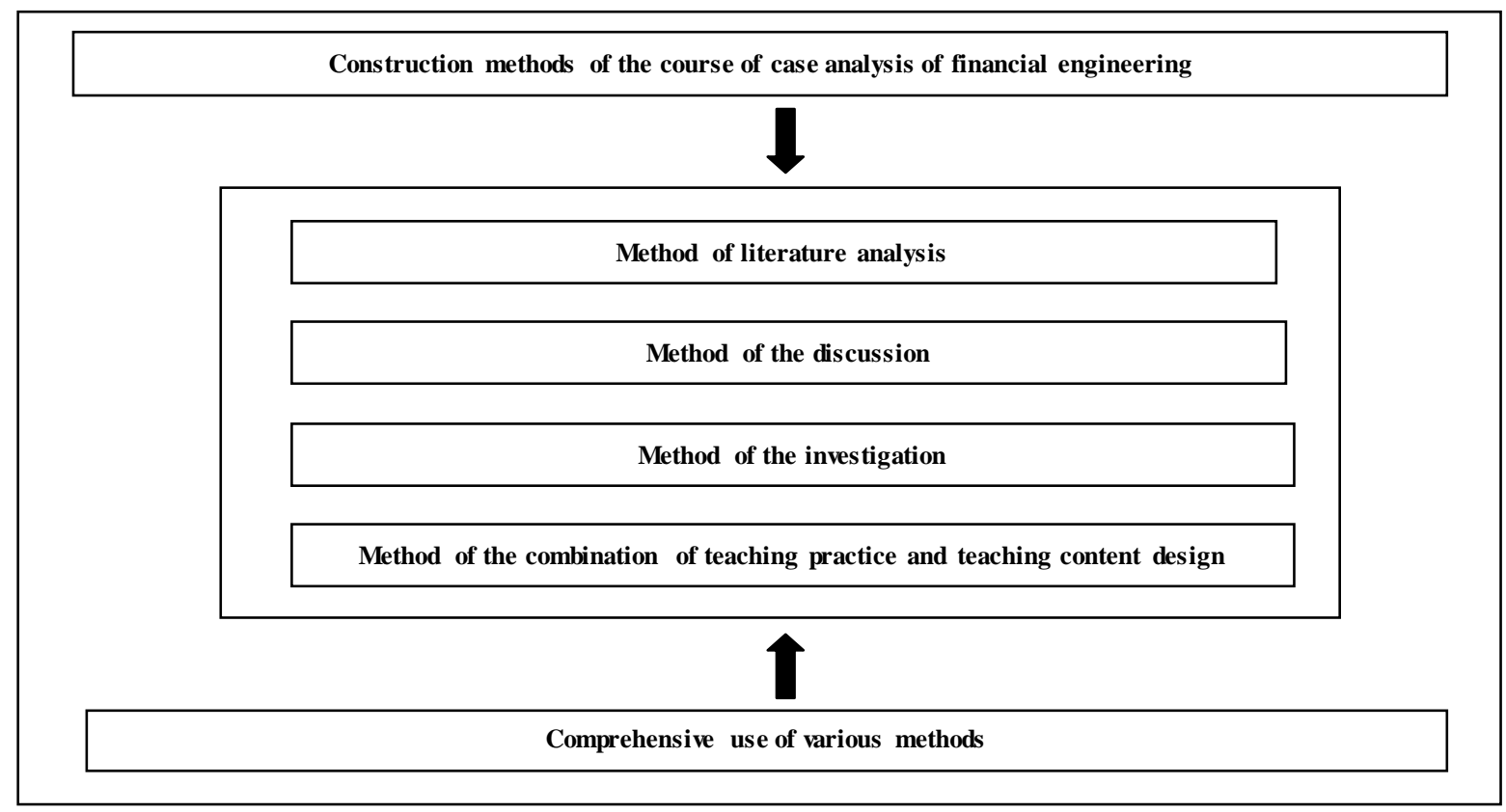

Fig. 2. Construction methods of case analysis of financial engineering

G. It is necessary to provide corresponding laboratory conditions to support the course construction of case analysis of financial engineering

In this paper, we adovcate to construct the course of case analysis of financial engineering with the consideration of the introductions of the programming design and financial modeling. In some time, the students need to download financial data. In such a case, the school should provide the corresponding laboratory conditions to support the course construction of case analysis of financial engineering. Take Nanjing University of Finances and Economics as an example. Nanjing University of Finances and Economics has built a financial engineering laboratory to support the corresponding teaching activities. Soft and hard conditions are sufficient to meet the experimental requirements of the course of case analysis of financial engineering. In the financial engineering laboratory, there are a variety of databases and computer software. For the databases, there is CSMAR research database, Wind financial consultation terminal, RESSET financial research database, EPS statistical data retrieval and prediction platform, CEIC economic database and so on. While for the corresponding computer software, there is Matlab numerical calculation and simulation software, C++ programming software, network analysis software and so on. Another important resource that should be provided is the computer. A common phenomenon in the laboratory is the obsolescence of computers and various problems in operation. There is no doubt that this will affect the teaching effect seriously. Therefore, computer maintenance and program updating need to be carried out frequently. Of course, this will produce a regular expenditure and not all the universities are willing to spend the money on this aspect. Considering that almost every student has a laptop, in such a case, an alternative method is to require students to bring their own laptop into the laboratory. What the laboratory does is to provide wireless network access and the integration of corresponding software. This method can reduce the expenditure of hardware of the laboratory. In sum, good experimental conditions are more likely to provide students with a relaxed and enjoyable learning atmosphere and it is necessary for the course construction of case analysis of financial engineering.

\section{H. Other principles that need to be paid attention to}

Other principles need to be paid much attention to in the construction process of the course of case analysis of financial engineering.

1) The combination of teaching and scientific research: The combination of teaching and scientific research is a very important principle that should be paid much attention to. The basic meaning of this principle is that introducing scientific research into the teaching process so as to make the teaching process become scientific research. At the same time, teaching activities need to be embodied in the process of scientific research so as to make the scientific research activities become teaching activities. In this way, the two main activities of colleges and universities are unified as one to realize the 
functions of colleges and universities [19]. To achieve this basic principle, on the one hand, it is necessary to make the students better know the teaching process rather than the corresponding conclusions. The teaching process should include the proposal of the problems, the way to solve them, the conclusion and the possible direction of the development [19]. In this way, the teaching activities are in line with the scientific research process. On the other hand, it is necessary to provide scientific research environment for students [19]. In the process of scientific research, teachers can enable students to participate in scientific projects and the students can also learn more knowledge. In addition, in the process of teaching, teachers can strengthen the examination of students' scientific research ability to stimulate the students' enthusiasm for scientific research [19]. In the course construction of case analysis of financial engineering, the combination of teaching and scientific research should be also paid much attention to. It is very important to put this principle into the practice of the course construction of case analysis of financial engineering.

2) Teacher-student interaction: The teaching is not the teacher's own work. It requires the joint action of students and teachers. Therefore, the setting of the course construction of case analysis of financial engineering should be beneficial to the interactions between teachers and students. While through the interactions between teachers and students, some aspects of the course can be adjusted to improve the course system of case analysis of financial engineering. Therefore, the "Teacher-student interaction" principle should also be paid much attention to in the course construction of case analysis of financial engineering

\section{SUMMARY}

In recent years, along with the continuous development of Chinese financial market, financial engineering as an emerging interdisciplinary science has been set up in more and more colleges and universities. Under this background, this paper analyzes the course construction path of case analysis of financial engineering from eight aspects, aiming at further consolidating and improving the professional skills of the students majoring in financial engineering. Of course, there are differences in teaching ideas and financial engineering training programs in different colleges and universities. Due to this point, there is no single teaching model that fits financial engineering majors in all colleges and universities. The course construction of case analysis of financial engineering should be combined with the orientation of the teaching idea of the specific university in addition with the consideration of the ability of the teacher team. At the same time, the course construction of case analysis of financial engineering should fit the development of local economy and meet the needs of students' development in future. In sum, a comprehensive consideration of multiple factors should be made in the course construction process of case analysis of financial engineering.

\section{REFERENCES}

[1] Zhang Zhenlong, Chen Rong. Financial engineering[M]. Higher Education Press,2012. (in Chinese)

[2] Wang Jinzhong. Cases of financial engineering[M].Southwestern University of Finance and Economics Press,2012. (in Chinese)

[3] Yang Junzhan. Application principles and cases of financial engineering[M]. Fudan University press, 2013. (in Chinese)

[4] Zhou Yujiang. Financial engineering: theory, practice and case [M].China Machine Press,2016. (in Chinese)

[5] Kumar A, Joshi L K, Pal A K, et al. MODWT based time scale decomposition analysis of BSE and NSE indexes financial time series[J]. International Journal of Mathematical Analysis, 2011, 5(27): 1343-1352.

[6] Deo M, Shah A. Scaling Properties of Systematic Risk: A New Evidence from Wavelet Analysis[J]. Asia-Pacific Journal of Management Research and Innovation, 2012, 8(3): 283-289.

[7] Alzahrani M, Masih M, Al-Titi O. Linear and non-linear Granger causality between oil spot and futures prices: A wavelet based test[J]. Journal of International Money and Finance, 2014, 48: 175-201.

[8] Di Clemente A. Estimating the Marginal Contribution to Systemic Risk by A CoVaR-model Based on Copula Functions and Extreme Value Theory[J]. Economic Notes, 2018, 47(1): 69-112.

[9] Razak R A, Is mail N. Risk of portfolio with simulated returns based on copula model[C]AIP Conference Proceedings. AIP, 2015, 1643(1): 219224.

[10] Sui X, He J, Li S. Research on the tail risk spillover between shanghai and shenzhen stock markets based on MODWT and time-varying Clayton Copula[C]Management Science \& Engineering (ICMSE), 2014 International Conference on. IEEE, 2014: 1135-1140.

[11] Constantin D, Clipici E. A new model for estimating the risk of bankruptcy of the insurance companies based on the artificial neural networks[J]. International Multidisciplinary Scientific Geo Conference: SGEM: Surveying Geology \& mining Ecology Management, 2016(1): 3-10.

[12] Aydin A D, Cavdar S C. Prediction of financial crisis with artificial neural network: an empirical analys is on Turkey[J]. International Journal of Financial Research, 2015, 6(4): 36.

[13] Sui X, Li L. Guarantee network model and risk contagion[J]. Chaos, Solitons \& Fractals, 2018, 106: 323-329.

[14] Sui X, He Jianmin. Research on the risk contagion between firms and banks based on the endogenous credit network with multi-agent[J]. Journal of Systems Science and Mathematical Sciences, 2017, 37(8): 1807-1819.

[15] Sun J, Li H, Chang P C, et al. The dynamic financial distress prediction method of EBW-VSTW-SVM[J]. Enterprise Information Systems, 2016, 10(6): 611-638.

[16] Yang J, Luo D. The P2P Risk Assessment Model Based on the Improved AdaBoost-SVM Algorithm[J]. Journal of Financial Risk Management, 2017, 6(02): 201.

[17] Hu Yinyi. The micro-credit company's financing "bottleneck" and the right of return on assets evaluation [J]. Reform2013 (6):135-143. (in Chinese)

[18] Huang Xingpeng, Le Yun. The situations, problems and solutions of the micro-credit company's financing [J]. Zhejiang Finance, 2013, (10):6366. (in Chinese)

[19] Zhou Chuan. Simplified higher education [M]. Hohai University Press and Nanjing Normal University press, 2016. (in Chinese) 